\title{
Functional Condition Rating Segment Sragen Ring Road South, Central Java Province
}

\author{
Rendy D. Pangesti ${ }^{1 *}$, Ary Setyawan ${ }^{2}$, Budi Yulianto ${ }^{3}$ \\ ${ }^{1}$ Graduate Students, Department of Civil Engineering, Universitas Sebelas Maret, Surakarta, Indonesia \\ ${ }^{2}$ Lecturer, Department of Civil Engineering, Universitas Sebelas Maret, Surakarta, Indonesia \\ ${ }^{3}$ Lecturer, Department of Civil Engineering, Universitas Sebelas Maret, Surakarta, Indonesia
}

\begin{abstract}
Assessment of pavement condition is functionally the most important aspect in determining road maintenance and repair activities, so that the financing can be monitored properly. There are two methods in handling the road assessment, ie visually and using tools. Visual assessment can use PASER and PCI. While IRI is a road assessment using Roadroid (Android Smartphone App) tool, where the tool will be used as national reference to get IRI value, because the cost is cheaper and effective. Therefore there needs to be a correlation between the three methods. Correlation in this research is divided into three, namely the correlation of PASER value with PCI, PASER with IRI, and PCI with IRI. The research location used as research object is South Ring Road Sragen. The result of the research was obtained, road assessment using PASER method with PCI resulted correlation value of pearson 0,51. Assessment of PASER with IRI has a correlation value of pearson 0,14. While the value of PCI with IRI yield correlation value pearson $-\mathbf{0 , 2 3}$. The value of the correlation coefficient between PASER and PCI has the highest value, since it has a nearly equal assessment approach by measuring the damage visually. The correlation of PCI with IRI is higher than PASER with IRI, thus proving that PCI assessment is more recommended because it can accommodate all types of road damage.
\end{abstract}

Keywords-PASER,PCI, IRI Roadroid.

\section{INTRODUCTION}

$I$ mplementation of road maintenance is part of the activities of road operations that serve as a monitor whether the road can be used performance both physically and its function. The district road is a supporter of a nationally integrated road network, which is where the road is required to meet established minimum service standards.

Puddles and excessive vehicle loads are external factors accelerating damage to roads resulting in low road life and are incompatible with the age of the plan. Internal factors (pavement carrying capacity) that is able to maintain the road is the most important, so the road is not too easily influenced by both external factors [1].

Asphalt PASER (Asphalt Pavement Surface Evaluation and Rating) is a simple survey on road surface asphalt quality. The system uses manual inspections visually to identify different types and extent of damage. Road assessment using PCI (Pavement Condition Index) is an assessment system of pavement conditions based on type, extent and extent of damage occurring and can be used as a reference in maintenance business (Suswandi et al, 2008). The assessment using PASER and PCI both uses manual inspections on the pavement. While IRI (International Roughness Index) is a road quality assessment that uses tools. Therefore there needs to be a comparison or correlation between the three methods. IRI is expressed in the amount of vertical change of road surface for each unit of road length $(\mathrm{m} / \mathrm{km})$. As for some tools that can be used to find the value of IRI is NAASRA Roughness meter, Roadroid (Android Smartphone Application) and others. IRI used in this study using IRI Roadroid, where the Roadroid tool forward is used as a national reference to get the value of IRI, because the cost is relatively cheap and effective.

The South Ring Road of Sragen is an alternative route that crosses inter districts located in Central Java, the road is regulated by Sragen regency. As an alternative route, the road is traversed by vehicles that have high traffic and loads of traffic. It is encouraging to do this research in order to know the functional road assessment in South Ring Road Street Sragen. This research is about to test the level of damage on road surface by using PASER, PCI, and IRI Roadroid method and comparison between the three methods.

\subsection{Objectives and Benefits}

The objective of this research is to know the condition of pavement assessment on South Ring Road of Sragen with PASER, PCI and IRI Roadroid assessment method. In addition, this study looks for correlations between PASER, PCI and IRI Roadriod road assessments on the assessment of functional road conditions.

\subsection{Literature Review}

Damage caused by freight loads that exceeds that specified is very large by the ratio of the amount of each load to the fourth rank and can reduce the life of the road pavement (Napitu, 2006).

Ignoring the slightly damaged asphalt surface will worsen the road surface from time to time. Maintenance and rehabilitation may slow or reverse the asphalt surface damage. The extent to which this occurs in the type of treatment or rehabilitation as well as the timing of the action. Maintenance such as filling and coating with priority of damaged roads with PASER measurements, can keep the surface in good condition 
August $1^{\text {st }}-2^{\text {nd }}$ 2017, Surabaya - Indonesia

and extend the life of the road service (Greg, 2015). The relationship between pavement and time can be seen in Figure 1.

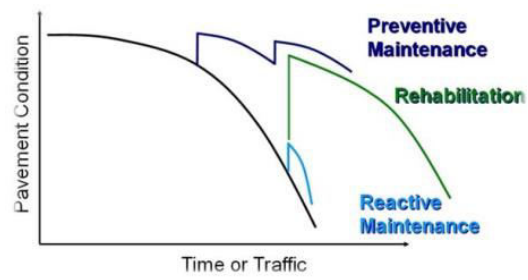

Figure 1. Relationship between Pavement and Time Conditions or Traffic

Source: Greg R., 2015

The PASER Guidelines are developed into a simplified rating system that can be used to survey road surface conditions. This is done because surface conditions can be considered one of the more important factors in PMS (Pavement Management System). The objective is to obtain information from the PASER survey relating to data types such as width, length, shoulder condition, and pavement type (Walker, 2002).

Stephen A. Arhin, et al. (2015) conducted a comparison between road functional assessment using the IRI and PCI methods. The study aims to reduce the subjectivity of PCI assessment, therefore the assessment also uses IRI. The research obtained $\mathrm{R}^{2}$ value that is 0,56 and 0,82 with margin error $5 \%$.

MR Schlotjes, et al. (2014) Roadroid can help manage road network assets at low cost to monitor and report on pavement conditions. The accuracy of the IRI and Roadroid assessment is possible at R2>0.85, but also depends on the speed and type of road (L. Forslof, 2015). Douangphachananh and Oneyama (2014) Acceleration of android smartphone data has a linear relationship with road roughness and significance of the relationship at the speed used.

\section{RESEARCH METHOD}

\subsection{PASER, PCI, IRI Roadroid Data Acquistion}

The research location used as the object of research is the segment of South Ring Road of Sragen divided into 5 parts of each segment has length: (1) $1 \mathrm{~km}$; (2) 1,3 km; (3) $0,6 \mathrm{~km}$; (4) $0,6 \mathrm{~km}$; (5) $1,3 \mathrm{~km}$ so the total length is $4,8 \mathrm{~km}$. The location of the road is located in Sragen regency of Central Java, where the road is traversed by large and heavy vehicles so it needs special action on the road. The pavement construction is an asphalt treated base (ATB).

Type of damage and dimensions damaged by. Equipment and Supplies. PASER and PCI. Assessment of road damage conditions in accordance with PASER and PCI methods, with PASER assessment with the following steps:

(1) Divide the road segment per $100 \mathrm{~m}$ on the road of research object,
(2) Determination and measurement of damage quantity,

(3) Evaluate roads according to road surface damage,

(4) Categorize rating or assessment of the quantity of road surface damage to values 1 to 10 taking into account the type and dimension of road damage.

The assessment of road conditions in accordance with Pavement Condition Index (PCI), as follows:

(1) Divide the road segment per $100 \mathrm{~m}$ on the road of research object,

(2) Measurement of the quantity of damage types,

(3) Determine the level of road damage that is low (low), medium (medium), high (high),

(4) Determining the level of damage (density,

(5) Determining the deduct value, according to the DV curve reading,

(6) Determining the Total Deduct Value (TDV),

(7) Determining Corrected Deduct Value (CDV), according to the reading of graphs of TDV and CDV relationships,

(8) Determining the PCI value of each segment

As for the roadroid IRI using android smartphone, car and camera. The survey steps using the Roadroid app are as follows:

(1) Install the holder on the inside of the car windshield to connect the smartphone, as shown in Figure 2 and then associate the smartphone in the holder. Smartphones can be in a horizontal or vertical position. After that make sure again that GPS and internet on smartphone is active.

(2) Setting the smartphone position by going into the settings menu, then select the fitting adjustment menu. After that then set the position of the smartphone until the value of $\mathrm{x}, \mathrm{y}$, and $\mathrm{z}$ in a green state as shown in Figure 3.

(3) The survey is done at the beginning of the road by pressing the Start / stop sampling menu then giving description of the road name to be surveyed and press OK. Ensure that when the survey vehicle runs it always maintains a minimum speed limit to maintain the validity of the survey results. After arriving at the end of the road then press Start / stop sampling menu. This process is shown as Figure 4.

(4) Uploading survey results for 2 times in the form of data and media. The data is the description of IRI survey results, while the media contains photographs of survey results. During this process make sure that the internet signal is in good condition. This process is shown in Figure 5.

\subsection{Statical Analysis}


Regional Conference in Civil Engineering RCCE)

The Third International Conference on Civil Engineering Research (ICCER)

August $1^{\text {st }}-2^{\text {nd }} 2017$, Surabaya - Indonesia

Statistics are defined as a method used in the collection and analysis of data which is a number so that

(1) Pearson Correlation Coefficient Analysis (r)

information can be obtained useful. Here is a statistical

Suspect of the relationship between variables in the population through the data relationships variables in the

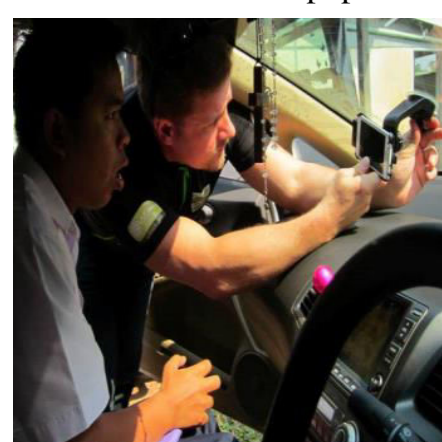

Figure 2. Installation of Holder

(Source: User Guide Roadroid, 2014)

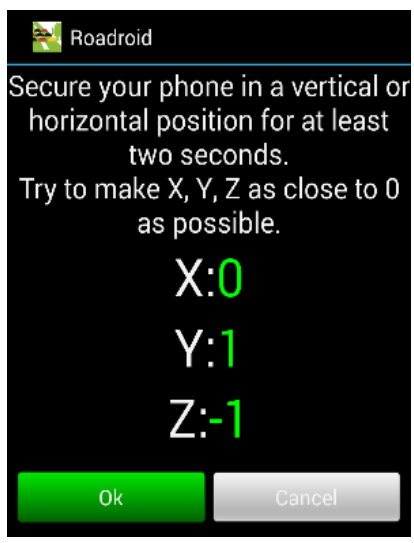

Figure 3. Setting the Smartphone Position

(Source: User Guide Roadroid, 2014)

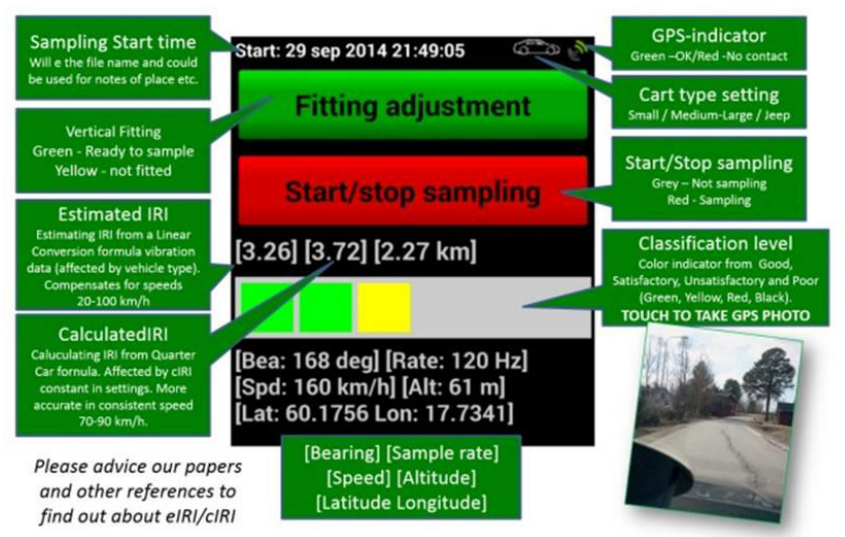

Figure 4. Start Surveys

(Source: User Guide Roadroid, 2014)
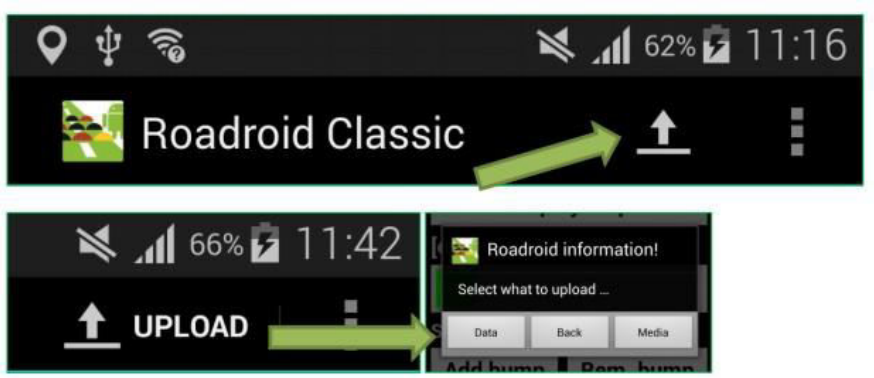

Figure 5. Upload Process of Survey Results (Source: User Guide Roadroid, 2014)

analysis done to obtain a comparison between the assessment of pavement using PASER, PCI, and IRI Roadroid: sample called associative hypothesis, then the first step to calculate the correlation coefficient between variables in the sample, then tested its significance. While the 
August $1^{\text {st }}-2^{\text {nd }}$ 2017, Surabaya - Indonesia

correlation is a number that shows the direction and strength of the relationship between two or more variables. Direction is expressed in the form of positive or negative relationship and the strength of the relationship is expressed in the magnitude of the correlation coefficient.The relationship of two or more variables is tested positive if the value of one variable is raised, it will raise another variable, and vice versa if one variable is lowered it will decrease the other variable. While if stated otherwise, if the value of one variable is increased, it will decrease another variable, and vice versa if one variable is lowered it will raise another variable.The strong relationship between the variables is expressed in the correlation coefficient, the value ranges from -1 to $1 \quad(-1<\mathrm{r}<1)$. If the value of correlation coefficient -1 or 1 , then the relationship between vaiabel is perfect, while the value of correlation coefficient 0 , then among these variables there is absolutely no relationship. The smaller the correlation coefficient, the greater the error of making the prediction. The direction of the relationship between two variables is divided into three, namely:

a Direct Correlation (Positive Correlation)

The change in one variable followed by another variable change regularly with the same direction of movement, with $\mathrm{r}=+1$.

b Inverse Correlation (Negative Correlation)

Changes to one variable are followed by another variable change regularly in the opposite direction of movement, with $\mathrm{r}=-1$.

c Nihil Correlation

Nihil Correlation is the absence of the direction of movement between the two variables tested or the direction of the relationship irregular, with the value $r=$ 0 .

This correlation coefficient technique is used to find the relationship and prove the hypothesis of two variables relationship when the data of two variables in the form of interval or ratio and data source two or more variables are the same. The equation used in the calculation of the correlation coefficient uses Equation 1.

$$
\mathrm{r}=\frac{\mathrm{n} \sum \mathrm{xi} \cdot \mathrm{yi}-\left(\sum \mathrm{xi}\right) \cdot\left(\sum \mathrm{yi}\right)}{\sqrt{\left[\left(\mathrm{n} \sum \mathrm{xi}^{2}\right)-\left(\sum \mathrm{xi}\right)^{2}\right] \cdot\left[\left(\mathrm{n} \sum \mathrm{yi}^{2}\right)-\left(\sum \mathrm{yi}\right)^{2}\right]}}
$$

Where xi: Value of variable $x$ (Assessment of functional path of method A); yi: y variable value (Road functional assessment method B); $\mathrm{n}$ : Amount of data.

Guidelines provide interpretation of correlation coefficients shown in Table 1.

Table 1. Interpretation of Correlation Coefficients

\begin{tabular}{c|c}
\hline $\begin{array}{c}\text { Correlation Coefficient } \\
\text { Value }(r)\end{array}$ & $\begin{array}{c}\text { Interpretation of Correlation } \\
\text { Coefficients }\end{array}$ \\
\hline $0,00-0,199$ & Very low \\
$0,20-0,399$ & Low \\
$0,40-0,599$ & Medium \\
$0,60-0,799$ & Strong \\
$0,80-1,000$ & Very Strong \\
\hline
\end{tabular}

Source: Sugiyono, 2013

\section{(2) Coefficient of Determination $\left(\mathrm{R}^{2}\right)$}

The coefficient of determination is the square of the correlation coefficient of pearson (r). This statistic is used to find out how much influence of variable $\mathrm{X}$ to variable $\mathrm{Y}$ or how much variation $\mathrm{Y}$ can be explained by
X. Calculation of correlation coefficient shown in Equation 2.

$\mathrm{R}^{2}=\frac{\mathrm{SSE}}{\mathrm{SST}}$

$\mathrm{SSE}=\sum_{\mathrm{i}=1}^{\mathrm{n}}(\mathrm{yi}-\hat{\mathrm{y}})^{2}$

$\mathrm{SST}=\sum_{\mathrm{i}=1}^{\mathrm{n}}(\mathrm{yi}-\overline{\mathrm{y}})^{2}$

by yi: Variable value y; y: The dependent variable is based on the value of xi; $\hat{y}$ : Average y value.

\section{(3) t-test}

t-test is done to find the correlation coefficient is significant $(\neq 0)$, which means there is a linear comparison between the two variables. Then determine the significant level of $0,95, \alpha=5 \%$ and calculate the test statistic using Equation 5 or by using the Excel Program help.

$\mathrm{t}_{\text {hit }}=\mathrm{r} \sqrt{\frac{\mathrm{n}-2}{1-\mathrm{r}^{2}}}$

With the above hypothesis, then created a rule with $\mathrm{H} 0$ rejected if $t_{\text {stat }}<-t_{\text {table }}$ or $t_{\text {stat }}>+t_{\text {table. }}$. It can be concluded that there is a linear correlation between the variables $\mathrm{x}$ and $\mathrm{y}$ in the population. Conversely, if thit enters the distribution area $t\left(-t_{\text {table }}<t_{\text {stat }}<+t_{\text {table }}\right)$, then there is no linear correlation between the variables $\mathrm{x}$ and $\mathrm{y}$ in the population.

\section{RESULTS AND DISCUSSION}

\subsection{Results Functional Condition Road PASER, PCI,} and IRI Roadroid

The location review used in this research is South Ring Road Sragen which is Sragen Regency Road, where the road is a road connecting Sragen regency. The acquisition of road functional conditions in this study each segment is divided into several segments, while the length of the segment is divided in every $100 \mathrm{~m}$.

\section{(1) Road Functional Condition Based on PASER}

The value of the PASER (Pavement Surface Evaluation and Rating) required a thorough survey of each review road segment, with the objective of obtaining the type and volume of road damage. To obtain PASER value every road damage is measured and recorded based on the type of damage that is on the road. Furthermore, based on the type and size of road damage, included in the PASER assessment to obtain a road assessment review. The result of measurement using PASER is done in 2016, PASER value on each road segment presented in Table 2.

\section{(2) Functional Condition of Road Based PCI}

The road assessment using PCI is done directly on the road of review, that is by measuring and recording based on the type of damage available in the field. The type and volume of damage to the road review using PCI is similar to the assessment using PASER, but the different assessment methods. PCI assessment is obtained with a scale of 0 to 100 , whereas the Asphalt PASER value is from 0 to 10 . For the purposes of research, the PCI value is converted into a rating from 0 to 10 or also called "base 10 PCI". The result of PCI value on the road section of the review can be seen in Table 3 . 
The Third International Conference on Civil Engineering Research (ICCER)

August $1^{\text {st }}-2^{\text {nd }}$ 2017, Surabaya - Indonesia

(3) Functional Condition of Road Based IRI Roadroid

Functional assessment using IRI can be determined by several tools. In this study, IRI values obtained by using the android smartphone tool with roadroid applications.

Table 2.

PASER Value per Segment

\begin{tabular}{ccc} 
Segment & PASER value & PASER Condition \\
\hline 1 & 6 & Good \\
2 & 6 & Good \\
3 & 7 & Good \\
4 & 6 & Good \\
5 & 7 & Good \\
\hline
\end{tabular}

Source: analysis

Table 3.

PCI Value per Segment

\begin{tabular}{|c|c|c|c|}
\hline Sgment & PCI Value & base $10 \mathrm{PCI}$ & PCI Condition \\
\hline 1 & 62,6 & 6,26 & Good \\
\hline 2 & 60,5 & 6,05 & Good \\
\hline 3 & 66,3 & 6,63 & Good \\
\hline 4 & 66,5 & $\begin{array}{c}6,65 \\
\text { Table } 4 .\end{array}$ & Good \\
\hline 5 & \multicolumn{3}{|c|}{ IRG,Roadroid VaGe per Segment Good } \\
\hline $\begin{array}{l}\text { Source: a } \\
\text { Segment }\end{array}$ & $\begin{array}{l}\text { IRI Road } \\
\text { alysis } \\
{ }_{\text {Segme }}\end{array}$ & $\begin{array}{l}\text { roid } \\
\text { nt }\end{array}$ & IRI Roadroid Condition \\
\hline 1 & 5,71 & & Medium \\
\hline 2 & 3,46 & & Good \\
\hline 3 & 2,42 & & Good \\
\hline 4 & 3,56 & & Good \\
\hline 5 & 3,79 & & Good \\
\hline
\end{tabular}

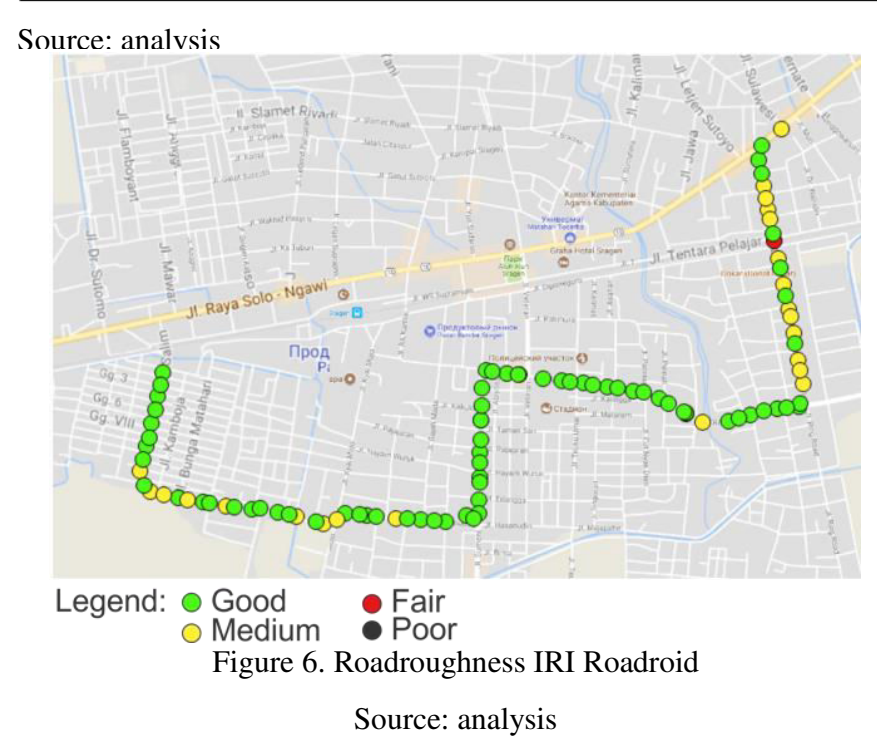

Use of this tool using a car as a vehicle tool at the time of the survey took place. The Roadroid IRI score can be seen in Table 4. Measurements of the Roadroid IRI score on the road can be seen in Figure 6, where the figure shows the level of unevenness of the road or road roughness. The image uses the help of QGIS 2.8.1 application.

\subsection{Descriptive Statistics}

The road functional assessment was divided into three combinations with the Pearson correlation coefficient (r), the coefficient of determination $\left(\mathrm{R}^{2}\right)$, and the tstat value of the t-test to determine whether there was a comparison between the three functional road assessment methods. Correlation calculations using CurveExpert professional application help. 
The Third International Conference on Civil Engineering Research (ICCER)

August $1^{\text {st }}-2^{\text {nd }}$ 2017, Surabaya - Indonesia

Data from PASER, PCI, and IRI of Roadroid are primary data, so the value of various road condition condition from each assessment method as shown in Table 5.

Table 6 can be obtained some correlation coefficient value, coefficient value, and tstat value in t test to know the comparison between the three methods, the explanation is as follows:

(1) Comparison of PASER and PCI values

The value of Pearson coefficient ( $r$ ) is 0,51 with the correlation equation $\mathrm{Y}=0,4915 \mathrm{x}+3,2622$ with $\mathrm{Y}=$ Base value $10 \mathrm{PCI}$ and $\mathrm{X}=\mathrm{PASER}$ value, determination coefficient value $\left(R^{2}\right)$ of 0,2597 , and $t_{\text {stat }}$ value $-0,085$ so there is a linear correlation with a moderate correlation level.

(2) Comparison of PASER and IRI value Roadroid
The value of Pearson coefficient ( $r$ ) of $-0,14$ with the correlation equation $\mathrm{Y}=-0,2183 \mathrm{x}+5,2909$ with $\mathrm{Y}=\mathrm{IRI}$ Roadroid and $\mathrm{X}=$ PASER value, determination coefficient value $\left(\mathrm{R}^{2}\right)$ of 0,0192 , and tstat value 7,397 and has a low correlation rate. The value of correlation is negative due to the reversal between PASER and IRI Roadroid ratings.

(3) Comparison of PCI and IRI Roadroid

Pearson coefficient ( $\mathrm{r}$ ) value of $-0,23$ with $\mathrm{Y}=$ $1,4805 \mathrm{x}-5,5697$ correlation with $\mathrm{Y}=$ base $10 \mathrm{PCI}$ and $\mathrm{X}$ $=$ IRI Roadroid, determination coefficient value $\left(\mathrm{R}^{2}\right)$ 0,8217 , and $\mathrm{t}_{\text {stat }}$ value 2,104 and has a low correlation rate. Negative correlation value is caused by reversed assessment between PCI and IRI Roadroid assessment. A summary of the results of the comparison analysis can be made graph with three combinations presented in Figure 7, Figure 8, and Figure 9.

Table 5. Value of PASER, PCI, and IRI Roadroid in the Year 2016

\begin{tabular}{c|c|c|c|c|c|c} 
Segment & PASER Value & \multicolumn{1}{c}{ PASER Condition } & \multicolumn{1}{c}{ base 10 PCI } & \multicolumn{1}{c}{ PCI Condition } & \multicolumn{1}{c}{ IRI Roadroid Value } & IRI Roadroid Condition \\
\hline 1 & 6 & Good & 6,26 & Good & 5,71 & Medium \\
2 & 6 & Good & 6,05 & Good & 3,46 & Good \\
3 & 7 & Good & 6,63 & Good & 2,42 & Good \\
4 & 6 & Good & 6,65 & Good & 3,56 & Good \\
5 & 7 & Good & 6,62 & Good & 3,79 & Good \\
\hline
\end{tabular}

Source: Analysis

Table 6. Summary of Analysis Calculations

\begin{tabular}{lcccccc}
\hline Correlation Type & r Value & Regression Equation & $\mathrm{R}^{2}$ Value & Critical Area & $\mathrm{t}$ stat & Conclusion \\
\hline Korelasi PASER dengan PCI & 0,51 & $0,4915 \mathrm{x}+3,2622$ & 0,2597 & $-2,011 \geq \mathrm{t} \leq 2,011$ & $-0,085$ & Correlation \\
Korelasi PASER dengan IRI Roadroid & $-0,14$ & $-0,2183 \mathrm{x}+5,2909$ & 0,0192 & $-2,011 \geq \mathrm{t} \leq 2,011$ & 7,397 & No Correlation \\
Korelasi PCI dengan IRI Roadroid & $-0,23$ & $1,4805 \mathrm{x}-5,5697$ & 0,8217 & $-2,011 \geq \mathrm{t} \leq 2,011$ & 2,104 & No Correlation \\
\hline
\end{tabular}

Source: Analysis

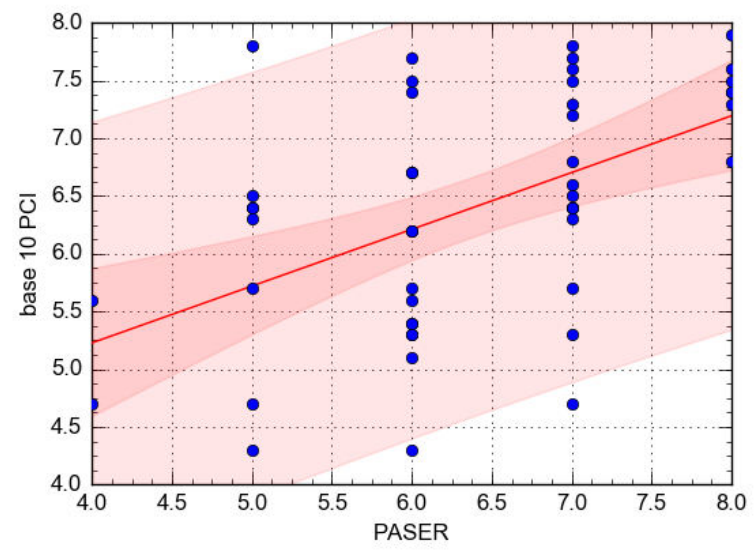

Figure 7. Graph of Correlation Between PASER and base 10 PCI Source: analysis 


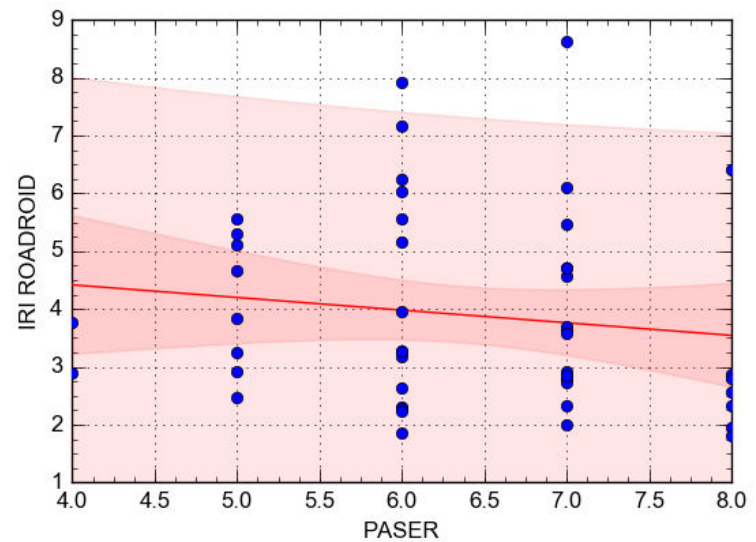

Figure 8. Graph of Correlation Between PASER and IRI Roadroid Source: analysis

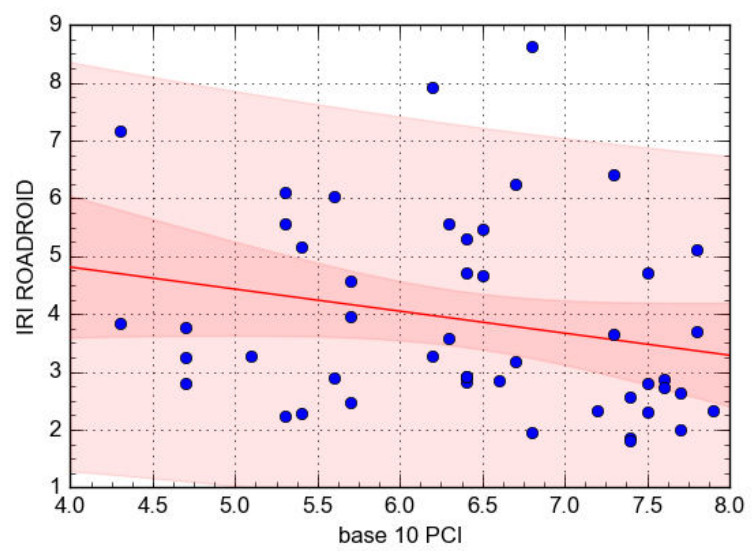

Figure 9. Graph of Correlation Between base 10 PCI and IRI Roadroid Source: analysis

\subsection{Discussion}

Table 6 shows the $r$ value column has negative correlation value, it can be interpreted the lower the IRI value of Roadriod then the PCI value will be higher and the lower the IRI value of the Roadroid the higher the PASER value. The value obtained in the analysis, can be summarized as follows:

Assessment using PASER, PCI, and IRI Roadroid yields the functional condition of the road, but uses different methods. Assessment of PASER and PCI, the assessment is done visually and measurements directly in the field, ie by choosing damage and measuring road damage on the road surface. While IRI Roadroid value using a tool in the form of Roadroid application paired on the smartphone, the assessment measures the comparison between the up and down the distance traversed vehicle vehicle wheels. IRI Roadroid value is intended to measure the comfort of driving.

The value of the correlation coefficient (r) on the relationship between PASER and PCI has the highest value compared to other correlation values. Because the two methods have a similar approach to road assessment, ie a direct damage survey. However, the assessment by the PCI method takes a relatively long time, because of the more complex types of damage.

The correlation value between PCI and IRI Roadroid is higher, compared to the correlation value between PASER and IRI Roadroid. This suggests that the use of PCI methods is recommended to be used in some surveys for assessment of functional road conditions, since the PCI method can accommodate all types of damage than the PASER method.

Road damage assessment and IRI's Roadroid value can be combined with other programs, namely KRMS (Regency Road Management System). KRMS is one of the road handling programs involving road components, road damage, and IRI Roadroid value

\section{CONCLUSION}

Based on the results of research and discussion about the assessment of functional conditions of South Ring Road in Sragen regency, it can be concluded that the assessment of road condition based on PASER value into the category of Good, PCI based assessment into the Good, the assessment using IRI Roadroid tool into the Good. While the correlation of road assessment between PASER and PCI resulted in Medium correlation, PASER assessment with IRI Roadroid had low correlation level, while PCI with IRI Roadroid resulted in Low correlation. There is a negative ( $r$ ) correlation between assessments using Asphalt PASER and IRI Roadroid value of -0.14 , and PCI with IRI Roadroid is -0.23 . The negative correlation shows that Asphalt PASER and PCI assessment with IRI Roadroid judgment reverses. The higher the Asphalt PASER or PCI value, the lower the Roadroid IRI value. While the correlation between Asphalt PASER and PCI has the highest value that is 0,51 , because the two assessment use approach which is 
August $1^{\text {st }}-2^{\text {nd }} 2017$, Surabaya - Indonesia

almost same, that is direct damage survey. The value of PCI correlation with IRI Roadroid has high value compared to Asphalt PASER correlation with IRI Roadroid, it indicates PCI assessment is more recommended because with that method can accommodate all road damage.

\section{ACKNOWLEDGEMENT}

The authors express their gratitude to the lecturers and civitas graduate of Civil Engineering University of Sebelas Maret who have helped, so that completed this research. Some of the opinions, findings, and conclusions or recommendations in this material are from the authors and do not necessarily reflect from the views of universities or colleges especially the Universitas Sebelas Maret.

\section{REFERENCES}

[1] D. Setijowarno, "Menuju Toleransi Nol Persen," 2008. County Road Association of Michigan Department of Transportation (CRAM MDOT). Not Dated (N.D.). PASER Road Condition Survey Demonstration Project.

[2] Douangphachanh, V. \& Oneyama, H. 2014. Using Smartphones to Estimate Road Pavement Condition. SMART Infrastructure Facility, University of Wollongong, Australia.

[3] Forslöf, Jones. 2014. Continuous Road Condition Monitoring with Smartphones. Roadroid AB.
[4] Greg R. Wendling, P.E. 2015.

Pavement Surface Evaluation And Rating Study

(PASER) Zionsville, Indiana.

[5] M. R. Schlotjes, A Visser, C Bennet. 2014. Evaluation of a smart phone roughness meter. University of Pretoria.

[6] Napitu,W. S. 2006. Kerusakan yang Timbul pada Jalan Raya Akibat Beban Angkutan yang Melebihi dari yang Ditetapkan. Jurnal Sistem Teknik Industri. v7 :104.

[7] S.W. Haider and M.B. Dwaikat, Estimating optimum timings for preventive maintenance treatments to mitigate pavement roughness,"Transportation Research Record", no. 2235, pp.4353, 2011.

[8] Stephen A. Arhin, Lakeasha N. Williams, Asteway Ribbiso, Melissa F. Anderson. 2015. Predicting Pavement Condition Index Using International Roughness Index in a Dense Urban Area. Journal of Civil Engineering Research 2015, 5(1): 10-17.

[9] Sugiyono. 2013. Metode Penelitian Kuantitatif Kualitatif dan R\&D. Bandung: Alfabeta.

[10] Sunset Hills, City of. "Pavement Management History"http://www.sunset-hills.com/Publicworks/ pavehist.html., Retrived January 2007.

[11] Suswandi. A. 2008. Evaluasi Tingkat Kerusakan Jalan dengan Methode Pavement Condition Index (PCI). Forum Teknik Sipil No. XVIII/ 3 September 2008.

[12] Walker, Donald, and Lynn Entine. 2002. PASER Asphalt Roads Manual. Madison, WI: Transportation Information Center, University of Wisconsin--Madison. 